\title{
Leaching and Mechanical Behaviour of Solidified/Stabilized Nickel Contaminated Soil with Cement and Geosta
}

\author{
Nicholas Hytiris ${ }^{1}$, Panagiotis Fotis ${ }^{1}$, Theodora-Dafni Stavraka1, ${ }^{1,}$ \\ Abdelkrim Bennabi ${ }^{2}$, Rabah Hamzaoui ${ }^{2}$ \\ ${ }^{1}$ Glasgow Caledonian University, School of Engineering \& Built Environment (SEBE), \\ Glasgow G4 0BA, United Kingdom. \\ N.Hytiris@gcu.ac.uk; Panagiotis.Fotis@gcu.uk \\ 2Université Paris-Est, Institut de Recherche en Constructibilité, ESTP, \\ 28 avenue du Président Wilson, 94234 Cachan, France. \\ tstavraka@adm.estp.fr; abennabi@adm.estp.fr; rhamzaoui@adm.estp.fr
}

\begin{abstract}
In the present work, solidification/stabilization (S/S) of nickel contaminated soil using Ordinary Portland CementOPC and commercial was carried out. Effects of different binder combinations of OPC and commercial stabilizer wt\% in the $S / S$ mix designs and physical and chemical characteristics of the treated samples were investigated. The mechanical property studied was unconfined compressive strength-UCS while chemical characterization of the samples was focused on the leachability of nickel. Results indicated that the optimum mix design, in terms of mechanical efficiency, was 10\% OPC wt\% and $4.2 w t \%$ commercial stabilizer while in terms of chemical efficiency 10\% OPC wt\% and 1.4 wt\% commercial stabilizer.
\end{abstract}

Keywords: Cement, Graded gravelly sand, Nickel, UCS, Leaching, S/S, Geosta ${ }^{\circledR}$ stabilizer.

(C) Copyright 2015 Authors - This is an Open Access article published under the Creative Commons Attribution License terms (http://creativecommons.org/licenses/by/3.0). Unrestricted use, distribution, and reproduction in any medium are permitted, provided the original work is properly cited.

\section{Introduction}

Stabilization/solidification (S/S) is one of the major methods in treating hazardous wastes prior to land disposal and also an effective technique for reducing the leachability of contaminants in soils like, heavy metals $[1,2]$. Entrapment of wastes that expresses hazardous characteristics within a cementitious matrix (solidification) and binding of contaminants (organic or inorganic) of a hazardous stream into a stable insoluble form (stabilization) are the mechanisms that best describe the principle behind solidification and stabilization $(\mathrm{S} / \mathrm{S})$ treatment. Solidification and stabilization (S/S) related processes such as chemical and physical stabilization of contaminants, dangerous to natural and build environment, have been identified as Best Demonstrated Available Technology-BDAT for 57 different hazardous wastes under the Resource Conservation and Recovery Act-RCRA [3, 4].

Heavy metals are well known to be toxic to most organisms and harmful to the environment when present in excessive concentrations $[5,6]$. Nickel has recently become a serious pollutant which is mainly released, from metal processing operations and from increased combustion of coal and oil [7]. Nickel is considered to be one of the most dangerous chemical elements, which may cause permanent soil contamination due to its specific physicochemical properties and mechanisms of action $[8,9]$.

Portland cements is the most commonly used primary binder for S/S matrix because it can restrict the mobility of heavy metals due to high $\mathrm{pH}$ and due to its capability to precipitate the metals in insoluble forms [1, 2]. Yin et al., 2008 [10] studied S/S of nickel hydroxide sludge using OPC and oil palm ash-OPA. They investigated the possibility to reduce the availability of $\mathrm{Ni}$ by increasing the amount of OPA and reducing the amount of OPC and found that the optimum mix design is $15 \mathrm{wt} \%$ OPA, $35 \mathrm{wt} \%$ OPC and $50 \mathrm{wt} \%$ sludge. Grega 
\& Domen, 2011 [11] examined the effectiveness of OPC, calcium aluminate cement-CAC, pozzolanic cement-PC and different additives in immobilizing $\mathrm{Cd}, \mathrm{Pb}, \mathrm{Zn}, \mathrm{Cu}, \mathrm{Ni}$ and As, in contaminated soil. The effectiveness was evaluated using leaching experiments, mechanical strength and geochemical modeling. Based on the model calculation, the most efficient S/S formulation was CAC + Akrimal@ (a cement repair mortar modified with aqueous acrylic polymer dispersion), which reduced soil leachability of Ni up to 4.7 times. Eisa et al., 2011 [12] investigated the immobilization of $\mathrm{Ni}(\mathrm{II})$ in various cement matrices (neat Portland cement in absence and presence of water reducing- and water repellingadmixtures as well as blended cement with kaolin) using the S/S technique. The degree of immobilization was assessed by using static mode and semi static mode of leaching and it was found to be very high (99\%).

Secondary binders could be described as materials that are not very effective on their own, when used in S/S methods, and are useful only when used in conjunction with lime or cement. Secondary additives are used mostly as stabilizers comprised of fly ash, zeolites, calcium or sodium or ammonium chlorides, enzymes, polymers, and potassium compounds. Several researches have shown that zeolites may be more suitable than other additives for the decontamination of soils polluted by heavy metals because they adjust soil $\mathrm{pH}$ value and as cation exchangers $[13,14]$. Shanableh \& Kharabsheh , 1996 [15] used a natural zeolite as additive to reduce the leaching of $\mathrm{Pb}^{2+}, \mathrm{Cd}^{2+}$ and $\mathrm{Ni}^{2+}$ from a contaminated soil and found that using up to $50 \%$ additive, nickel leaching was reduced by a maximum of approximately 50\%. Belviso et al., 2010 [16] in their study, used an artificially Ni contaminated soil, treated with coal fly ash for synthesizing zeolite at low temperatures and they found that newly-formed zeolites reduce the toxicity of the element in the polluted soil. Table 1 shows all the research works reported until now in this section.

Table 1. All research works reported in introduction section.

\begin{tabular}{|c|c|c|c|c|c|c|}
\hline \multirow{2}{*}{ Research work } & \multicolumn{2}{|c|}{ Binders } & \multirow{2}{*}{ Optimum contents } & \multirow{2}{*}{ Water/Binder Ratio } & \multirow{2}{*}{ Additives } & \multirow{2}{*}{ Tests } \\
\hline & Primary & Secondary & & & & \\
\hline Yin et al., 2007 & $\mathrm{OPC}$ & OPA & $\begin{array}{l}50 \text { wt } \% \text { sludge, } \\
15 \text { wt } \% \text { OPA, } \\
35 \text { wt } \% \text { OPC }\end{array}$ & 0,45 & & $\begin{array}{l}\text { *UCS } \\
\text { *Leaching method (TCLP) } \\
\text { *Atomic Absorption } \\
\text { Spectrometer (AAS) } \\
\text { *XRD }\end{array}$ \\
\hline $\begin{array}{c}\text { Grega \& Domen, } \\
2011\end{array}$ & $\begin{array}{c}\text { OPC } \\
\text { PC } \\
\text { CAC }\end{array}$ & & $\begin{array}{l}67 \% \text { soil, } \\
10 \% \text { CAC, } \\
1.39 \% \text { Akrimal }\end{array}$ & 0.29 & $\begin{array}{l}\text { *Cement plasticizers } \\
\text { *Fibrous material } \\
\text { polypropylene fibers } \\
\text { *Aqueous acrylic } \\
\text { polymer dispersion } \\
\text { Akrimal-E® } \\
\end{array}$ & $\begin{array}{l}\text { *UCS } \\
\text { *Leaching method (TCLP) } \\
\text { * PTMs mass transfer } \\
\text { (modeling) } \\
\text { *Statixtical analysis }\end{array}$ \\
\hline Eisa et al., 2011 & $\mathrm{OPC}$ & Kaolinite & $\begin{array}{l}\text { The degree of } \\
\text { immobilization of } \\
\mathrm{Ni}(\mathrm{II}) \text { in the various } \\
\text { used cement pastes } \\
\text { was very high }\end{array}$ & $\begin{array}{l}* 0.28 \text { (without } \\
\text { superplasticizer) } \\
* 0.24 \text { (with } \\
\text { supeplasticizer) }\end{array}$ & $\begin{array}{l}\text { *Superplasticizer } \\
\text { *Calcium stearate }\end{array}$ & $\begin{array}{l}\text { *UCS } \\
\text { *Tank leaching }\end{array}$ \\
\hline $\begin{array}{c}\text { Shanableh \& } \\
\text { Kharabsheh, } \\
1996\end{array}$ & & & $\begin{array}{c}\text { Nickel leaching } \\
\text { was reduced by a } \\
\text { maximum of } \\
\text { approximately } \\
50 \% \text { zeolite } \\
\end{array}$ & & *Zeolite & *Leaching method (TCLP) \\
\hline $\begin{array}{l}\text { Belviso et al., } \\
2010\end{array}$ & $\begin{array}{c}\text { *Coal fly } \\
\text { ash }\end{array}$ & & $\begin{array}{l}\text { Newly-formed } \\
\text { zeolites reduce the } \\
\text { toxicity of the } \\
\text { element in the } \\
\text { polluted soil }\end{array}$ & & $* \mathrm{NaOH}$ & $\begin{array}{l}\text { *Bench-scale experiments } \\
\text { *XRD } \\
\text { *BCR three-step sequential } \\
\text { extraction }\end{array}$ \\
\hline
\end{tabular}


The aim of this work was to use OPC and Geosta $®$ at different binder combinations in order to study the strength development as well the leachability aspects of OPC -treated Ni contaminated soil.

\section{Materials and Methods}

The experiments were carried out using an artificially restored and polluted soil. For soil, the particle size distribution (ASTM D6913) and the British Standard light compaction test (BS 1377) were applied. After particle size analysis, the soil consisting of $60 \%$ of sand (ranging between fine, medium and coarse sand) and $40 \%$ of fine gravel. Therefore, the soil could be described as a well graded gravelly sand. Regarding the compaction test, the values of optimum water content and maximum dry density were $8.1 \%$ and $1724 \mathrm{~kg} / \mathrm{m}^{3}$, respectively. The nickel used was Nickel (II) sulfate hexahydrate $\left(\mathrm{NiSO}_{4} 6 \mathrm{H}_{2} \mathrm{O}\right)$ which had a solubility of 625 $\mathrm{g} / \mathrm{l}$ at $20^{\circ} \mathrm{C}$ and a final concentration of $2300 \mathrm{mg} / \mathrm{kg}$ by weight of soil. The experimental program consisted of one primary binder (Medium strength, type I 35/A OPC) at different quantities $(5 \%, 7.5 \%$ and $10 \%$ by dry weight of the soil) and Geosta ${ }^{\circledR}$ at $1.4 \%$ (100gr), 2.8\% (200gr) and $4.2 \%$ (300gr) (by dry weight of the soil). A water to soil ratio of 0.1 was used. Geosta ${ }^{\circledR}$ was a secondary stabilization agent consisting of artificial zeolites A4, chlorides and alkalis. Table2 reflects the mix design symbol used for each mixture. Geosta ${ }^{\circledR}$ chemical composition is shown in Table 3.

Table 2. Mix design symbol for each mixture. Mix design symbol

\section{5\% OPC}

$5 \%$ OPC

$5 \%$ OPC-1.4\% G

$5 \%$ OPC- $2.8 \% \mathrm{G}$

$5 \%$ OPC- $4.2 \% \mathrm{G}$

\section{$7.5 \%$ OPC}

$7.5 \%$ OPC

$7.5 \%$ OPC $-1.4 \% \mathrm{G}$

$7.5 \%$ OPC- $2.8 \% \mathrm{G}$

$7.5 \%$ OPC- $4.2 \% \mathrm{G}$

\section{$10 \%$ OPC}

$10 \%$ OPC

$10 \%$ OPC- $1.4 \% \mathrm{G}$

$10 \%$ OPC $-2.8 \% \mathrm{G}$

$10 \%$ OPC- $4.2 \% \mathrm{G}$

$$
\text { OPC = Ordinary Portland Cement, } G=\text { Geosta } ®
$$
stabilizer
Table 3. Chemical composition of Geosta $®$.

\begin{tabular}{|c|c|c|c|}
\hline Component & $\begin{array}{l}\text { Quantity } \\
(\%)\end{array}$ & Component & $\begin{array}{l}\text { Quantity } \\
\text { (\%) }\end{array}$ \\
\hline $\begin{array}{l}\mathrm{MgCl}_{2} \cdot 6 \mathrm{H}_{2} \mathrm{O} \\
\text { (tech. pure) }\end{array}$ & 14.00 & $\mathrm{FeCl}_{2}$ & 3.00 \\
\hline $\begin{array}{l}\mathrm{NaCl} \text { (tech. } \\
\text { pure) }\end{array}$ & 13.00 & $\mathrm{KHCO}_{3}$ & 2.80 \\
\hline $\mathrm{KCl}$ (tech. pure) & 11.60 & $\begin{array}{l}{\mathrm{Amorphous} \mathrm{SiO}_{2}}_{(5-40 \mu \mathrm{m})}\end{array}$ & 2.55 \\
\hline $\begin{array}{l}\mathrm{CaCl}_{2 \cdot 2} \mathrm{H}_{2} \mathrm{O} \text { (tech. } \\
\text { pure) }\end{array}$ & 10.00 & $\mathrm{Na}_{2} \mathrm{SO}_{4}$ & 2.00 \\
\hline $\begin{array}{l}\text { Synthetic } \\
\text { Zeolite A4 }\end{array}$ & 9.17 & $\mathrm{FeSO}_{4}$ & 1.02 \\
\hline $\begin{array}{l}\mathrm{K}_{2} \mathrm{CO}_{3} \text { (tech. } \\
\text { pure) }\end{array}$ & 5.10 & $\mathrm{Al}_{2}\left(\mathrm{SO}_{4}\right)_{3}$ & 0.31 \\
\hline $\begin{array}{l}\text { MgO (tech. } \\
\text { pure) }\end{array}$ & 5.00 & Cobalt & 0.31 \\
\hline $\begin{array}{l}\mathrm{Na}_{2} \mathrm{~S}_{2} \mathrm{O}_{3} \\
\text { (Thiosulphate) }\end{array}$ & 3.40 & $\begin{array}{l}\text { Confidential } \\
\text { component(s) }\end{array}$ & 16.75 \\
\hline
\end{tabular}

Prior to mixing, soil sample was allowed to dry in a pre-heated oven for 24 hours and at $105{ }^{\circ} \mathrm{C}$. The dried soil was then placed in the mechanical mixer which thoroughly mixed the uncontaminated soil in order to homogenize particle distribution. During the mixing process of the uncontaminated soil and after 2 minutes, OPC was added and the admixture was allowed to mix for another 2 minutes. Having ensured by now an even distribution among soil and cement particles, contaminant solution was poured over the admixture and the mixing process was allowed to run for another 10 minutes. While the mixing procedure was still active, the weight of cubical moulds was determined and recorded. With the completion of the mixing process, the moulds were filled with the admixture, which was compacted in three layers. For the mixtures containing Geosta ${ }^{\circledR}$, Geosta ${ }^{\circledR}$ powder (different quantity for each mixture) was added 5 minutes prior the end of the mixing procedure. The mass of the moulds with the compacted contaminated soil was again determined and recorded. The moulds were then covered with a plastic film and allowed to solidify for 24 hours. After 28 days of curing time, S/S samples were subjected to the standard protocol of the Leaching Characteristics Of Moulded Or 
Monolithic Building And Waste Materials, "The Tank Test" (17) (Environmental Agency UK, 2004). The leaching experiments were performed at room temperature, $\left(\sim 24.8^{\circ} \mathrm{C}\right)$. The specimen tank (plastic container, with Width $=240 \mathrm{~mm}$, Height $=180 \mathrm{~mm}$ and Length $=290 \mathrm{~mm}$ ) was filled with distilled water to achieve a liquid to solid ratio (L/S) of 5:1. The leachate was removed and replaced after $0.25,1.0,2.25,4.0,9.0$, $16.0,32.0$ and 64.0 days (giving a total leaching time of $\sim 128$ days). Then the samples were collected and centrifuged at a speed of $10,000 \mathrm{rpm}$ for $10 \mathrm{~min}$. The supernatant was then analyzed, through a Flame Atomic Absorption Spectrometer (FAAS) and according to DIN 38406 [18].

Cube specimens of $100 \times 100 \times 100 \mathrm{~mm}$ were used for UCS test of the pastes. UCS was determined at 156 days in order to obtain the same time of curing as the leaching samples (28 days of air curing at $25^{\circ} \mathrm{C}$ and then a leaching period of 128 days) according to ASTM 2166. UCS was the average value of three samples. The test was carried out with a MTS machine of $100 \mathrm{kN}$ for small values and an MTS machine of $300 \mathrm{kN}$ for high values. The constant rate applied on both MTS machines is 1 $\mathrm{mm} / \mathrm{min}$.

\section{Results and Discussion}

Table 4 lists the S/S waste acceptance criteria which are utilized to assess the effectiveness of the treatment. The leachability limits are extracted from the Interdepartmental Committee on Redevelopment of Contaminated Land (ICRCL) while the UCS limits are extracted from regulatory waste limit at a disposal site in the United Kingdom.

Table 4. Stabilized/solidified waste acceptance criteria for $\mathrm{Ni}$ concerning UCS and leachability.

\begin{tabular}{llc}
\multicolumn{1}{c}{ Indicators } & \multicolumn{1}{c}{$\begin{array}{c}\text { Regulatory } \\
\text { (acceptance) }\end{array}$} & Level \\
\hline $\begin{array}{l}\text { UCS at 28-day of } \\
\text { curing }\end{array}$ & $\begin{array}{l}\text { Landfill disposal } \\
\text { limit }\end{array}$ & $0.34(\mathrm{MPa})$ \\
& Residential & $130(\mathrm{mg} / \mathrm{kg})$ \\
Ni Leachability & Allotment & $230(\mathrm{mg} / \mathrm{kg})$ \\
& Commercial & $1800(\mathrm{mg} / \mathrm{kg})$
\end{tabular}

\subsection{Leachability}

The cumulative leach values of 5, 7.5 and $10 \%$ OPCGeosta ${ }^{\circledR}$ mix designs, in $\mathrm{mg} / \mathrm{l}$, are plotted against time, in days, in Fig.1 (a, b, c) respectively. The poor environmental performance of only OPC mixtures is evident when compared to the mixtures containing Geosta $\AA$, however, all mixtures seem to have a downward tendency towards Ni release.

This poor environmental performance in the absence of Geosta ${ }^{\circledR}$ relies on its chemical composition (see Table 3). Geosta ${ }^{\circledR}$ is mainly composed of chlorides $\left(\mathrm{MgCl}, \mathrm{NaCl}, \mathrm{KCl}\right.$, and $\left.\mathrm{CaCl}_{2}\right)$ and zeolites. As it has already mentioned these chlorides are good stabilizers. The key mechanism involved in producing stabilization is ion exchange between soil-cement constituents and chlorides of Geosta ${ }^{\circledR}$. More specifically, when clay particles (usually negatively charged) are covered with like-charged particles they repel each other, but if some particles have unlike charges, they attract. Then a displacement of sorbed heavy metals occurs and leads to a formation of heavy metal-Cl complexes [19,20].

The second essential compound of Geosta ${ }^{\circledR}$ is the zeolite. Zeolites are a class of alkaline porous aluminosilicates [13] with permanent negative charges on their surfaces. They have a high cation exchange capacity because their structure is made of a framework of $\mathrm{SiO}_{4}$ and $\mathrm{AlO}_{4}$ tetrahedra with a replacement of $\mathrm{Si}^{4+}$ by $\mathrm{Al}^{3+}$ and as a result they are natural cation exchangers and appropriate to remove toxic cations $[13,14]$. In fact this negative charge is balanced by exchangeable cations like calcium, potassium or sodium. On their turn these cations are exchangeable with the heavy metal cations [21]. As a consequence, heavy metals can be trapped inside the zeolitic structure [22]. Due to these effects the environmental performance with the addition of Geosta ${ }^{\circledR}$ is more effective and this becomes clearer in Fig. 2, where the cumulative measured leaching for $\mathrm{Ni}$, for all mix designs, is presented.

For every cube specimen was used $2.33 \mathrm{~kg}$ of soil, thus $136 \mathrm{mg}$ of Ni were leached from every cube. The degree of contamination was fixed to $2300 \mathrm{mg} / \mathrm{kg}$ by weight of soil; as a consequence every cube contains $5359 \mathrm{mg}$ :

$2300 \mathrm{mg} / \mathrm{kg} \mathrm{X} 2.33 \mathrm{~kg}=5359 \mathrm{mg}$.

The difference between $5359 \mathrm{mg}$ and $136 \mathrm{mg}$ is the amount of Ni that entrapped into the sample's structure:

$5359 \mathrm{mg}-136 \mathrm{mg}=5223 \mathrm{mg}$.

In order to find the quantity of $\mathrm{Ni}$ entrapped into the structure in $\mathrm{mg} / \mathrm{kg}$, the $5223 \mathrm{mg}$ had been divided by the weight of soil per cube:

$$
5223 \mathrm{mg} / 2.33 \mathrm{~kg}=2241.6 \mathrm{mg} / \mathrm{kg} \text {. }
$$




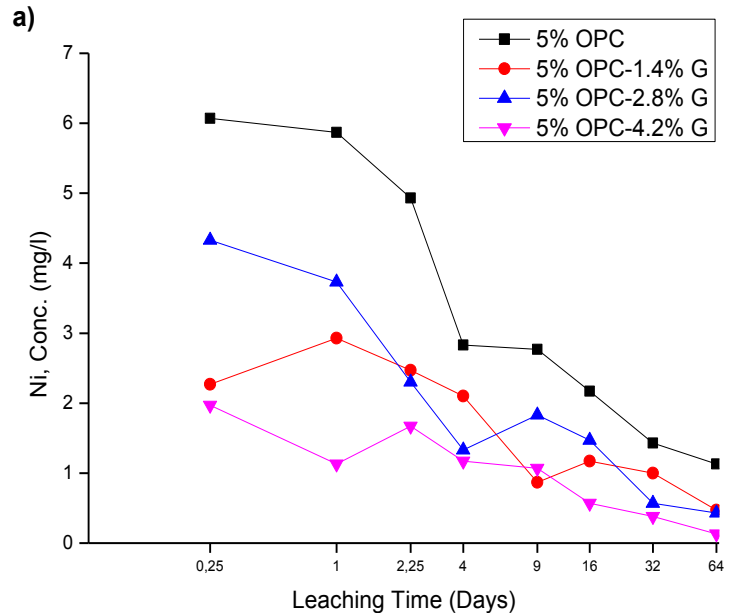

(a)

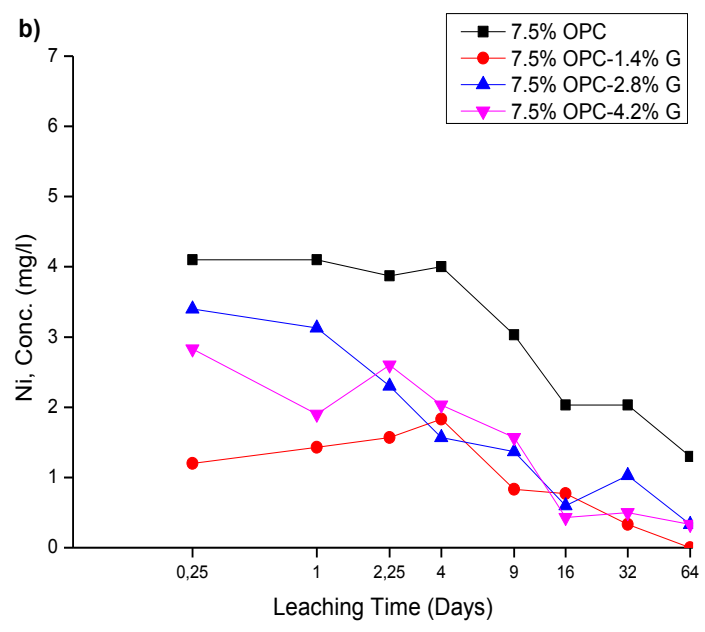

(b)

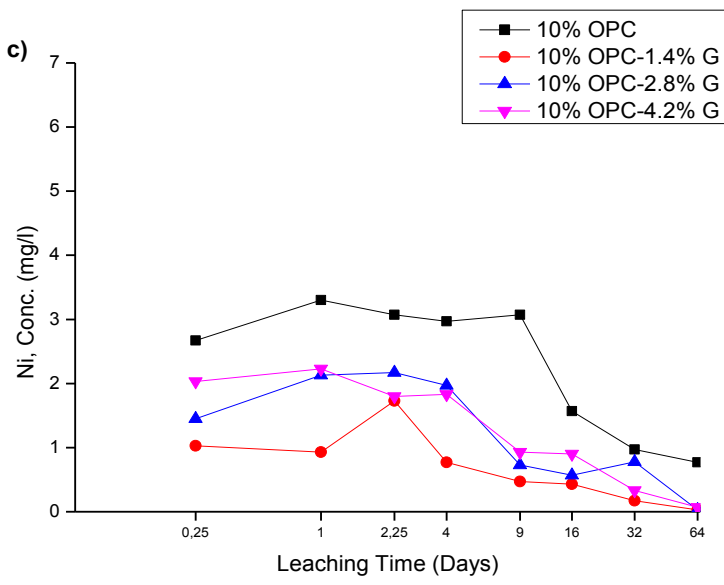

(c)

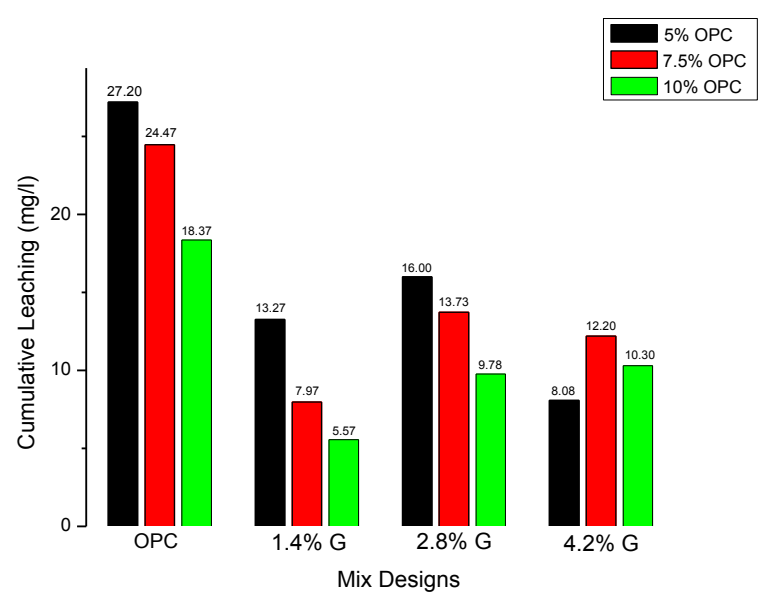

Figure 2. Cumulative Leaching of Ni mix designs.

Hence, $2241.6 \mathrm{mg} / \mathrm{kg}$ of contaminant were not leached while $58.4 \mathrm{mg} / \mathrm{kg}$ were leached $(\mathrm{Ni}$ contamination below the trigger values proposed by ICRCL). Finally, the 5\%OPC-4.2\%G mixture was proved more efficient in $\mathrm{Ni}$ confinement within its solidified matrix, since it was the only mixture that managed to maintain Ni leakage quite low $8.08 \mathrm{mg} / \mathrm{l}(17.34 \mathrm{mg} / \mathrm{kg})$.

Table 5 summarizes the leachability values in $\mathrm{mg} / \mathrm{l}$ and $\mathrm{mg} / \mathrm{kg}$, in order to be easier to compare leaching results to waste acceptance criteria of Table 4. Moreover, Table 5 shows the ratio of stabilization for all mixtures.

Table 5. Leachability in $\mathrm{mg} / \mathrm{kg}, \mathrm{mg} / \mathrm{l}$ and ratio of stabilization.

$$
\text { Mix Design Leachability Ratio of }
$$
$(\mathrm{mg} / \mathrm{l}) \quad(\mathrm{mg} / \mathrm{kg}) \quad$ Stabilization (\%)

\begin{tabular}{cccc}
\hline $5 \%$ OPC & 27.20 & 58.38 & 97.46 \\
$5 \%$ OPC-1.4\% G & 13.27 & 28.48 & 98.76 \\
$5 \%$ OPC-2.8\% G & 16.00 & 34.33 & 98.51 \\
$5 \%$ OPC-4.2\% G & 8.08 & 17.34 & 99.25 \\
$7.5 \%$ OPC & 24.47 & 52.51 & 97.71 \\
$7.5 \%$ OPC-1.4\% & 7.97 & 17.10 & 99.48 \\
G & & & \\
$7.5 \%$ OPC-2.8\% & 13.73 & 29.46 & 98.71 \\
G & & & \\
$7.5 \%$ OPC- $4.2 \%$ & 12.20 & 26.18 & 98.86 \\
G & & & \\
$10 \%$ OPC & 18.37 & 39.42 & 98.28 \\
$10 \%$ OPC-1.4\% G & 5.57 & 11.95 & 99.50 \\
$10 \%$ OPC-2.8\% G & 9.78 & 21.00 & 99.08 \\
$10 \%$ OPC-4.2\% G & 10.30 & 22.10 & 99.03 \\
\hline
\end{tabular}

Figure 1. Ni concentration (mg/l) and leaching time (days), for a) $5 \%$ OPC, b) $7.5 \%$ OPC, c) $10 \%$ OPC. 
In mix design containing 7.5\% OPC (see Fig 1b), a comparison of the environmental performance of all mixtures, strengthens the earlier observation over the poor ability of cement-only mixture $(7.5 \% \mathrm{OPC})$ to restrain Ni release. Furthermore, Geosta ${ }^{\circledR}$ mixtures $7.5 \% \mathrm{OPC}-1.4 \% \mathrm{G}$ and $7.5 \% \mathrm{OPC}-4.2 \% \mathrm{G}$, although are proved capable in $\mathrm{Ni}$ immobilisation when compared to $7.5 \% \mathrm{OPC}$, their behaviour seems to be reversed when compared to their environmental performance in the previous mix design (5\% OPC). Mixture, 7.5\%OPC$1.4 \% \mathrm{G}$ shows optimum $\mathrm{Ni}$ restrainment in its cementitious matrix while, $7.5 \% \mathrm{OPC}-2.8 \% \mathrm{G}$ and 7.5\%OPC-4.2\%G exhibit similar behaviour.

In mix design containing 10\% OPC (see Fig 1c); the difference in Ni release is also obvious between the OPC and the Geosta ${ }^{\circledR}$ containing mixtures. Ni release for all mixtures is lower when compared to 5\% OPC and $7.5 \%$ OPC mix designs, indicating that the increase in cement $(10 \% \mathrm{w} / \mathrm{w})$ has a critical role in Ni release from solidified material. The cumulative release of $10 \% \mathrm{OPC}$ mix design (Fig.2), verifies the previous statement, since all mixtures achieve better environmental performance when compared to 5\% OPC mix design and $7.5 \%$ OPC mix design. However, as in previous mix design $(7.5 \%$ OPC), mixture $10 \% \mathrm{OPC}-1.4 \% \mathrm{G}$ demonstrates optimum $\mathrm{Ni}$ retention ability $(5.57 \mathrm{mg} / \mathrm{l}$ or $11.95 \mathrm{mg} / \mathrm{kg})$ while, 10\%OPC-2.8\%G and 10\%OPC-4.2\%G performed in an antagonistic, although similar manner, by reaching cumulative concentrations of $9.78 \mathrm{mg} / \mathrm{l}(21.00 \mathrm{mg} / \mathrm{kg})$ and $10.3 \mathrm{mg} / \mathrm{l}(22.10 \mathrm{mg} / \mathrm{kg})$, respectively.

\subsection{Mechanical Properties}

The long-term viability of S/S waste was further assessed by analysing the mechanical performance of the S/S material. Fig.3 (a, b, c) shows the UCS-strain relation for the samples studied and Table 5 the values of UCS and elastic modulus (elastic modulus is defined as the slope of its stress-strain curve in the elastic deformation region).

It is evident that higher compressive strength values were obtained when higher amount of cement (OPC) was used for the solidification process. The mix design containing $10 \%$ of OPC has presented values almost three times higher than the mix design containing 7.5\% OPC and four times higher when compared to the mix design containing 5\% OPC. This effect could be attributed to the fact that by increasing the cement quantity, the amount of $\mathrm{C}_{3} \mathrm{~S}$ (tricalcium silicate) and $\mathrm{C}_{2} \mathrm{~S}$ (dicalcium silicate) increased in the stabilized soil enabling more production of calcium-silicate-hydrate (C-S-H) [3].

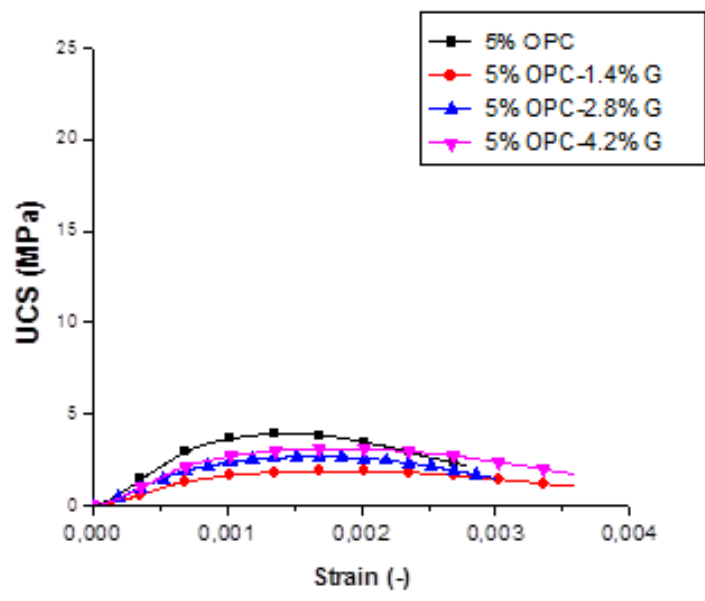

(a)

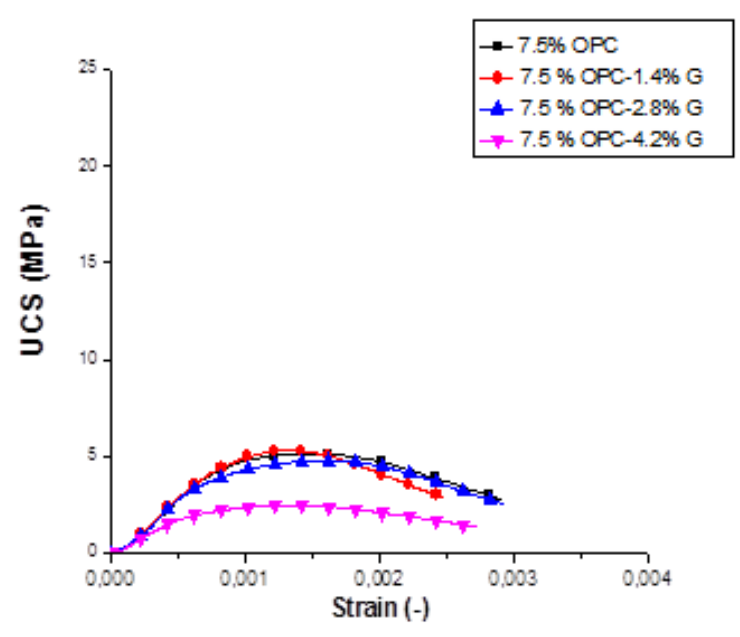

(b)

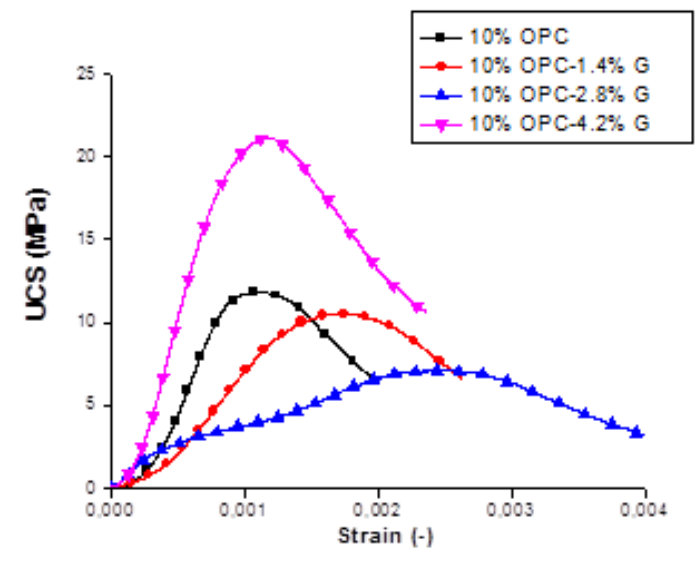

(c)

Figure 3. UCS-strain relation of Ni contaminated soil, treated with OPC and Geosta®: (a) 5\%, (b) 7.5\%, (c): 10\%. 
Table 6. Elastic Modulus and UCS of mix designs.

\begin{tabular}{clc}
\hline $\begin{array}{c}\text { UCS (MPa) } \\
\pm 1.00\end{array}$ & \multicolumn{1}{c}{ Mix Design } & \multicolumn{2}{c}{$\begin{array}{c}\text { Elastic } \\
\text { modulus } \\
(\mathrm{GPa})\end{array}$} & \pm 1.00 \\
\hline 3.90 & $5 \%$ OPC & 4.20 \\
1.90 & $5 \%$ OPC-1.4\% G & 1.75 \\
2.70 & $5 \%$ OPC-2.8\% G & 2.75 \\
& $5 \%$ OPC-4.2\% G & 2.84 \\
5.10 & $7.5 \%$ OPC & 5.46 \\
5.30 & $7.5 \%$ OPC-1.4\% G & 5.70 \\
4.80 & $7.5 \%$ OPC- $2.8 \% \mathrm{G}$ & 5.28 \\
2.50 & $7.5 \%$ OPC-4.2\% G & 3.45 \\
11.84 & $10 \%$ OPC & 11.80 \\
10.51 & $10 \%$ OPC-1.4\% G & 6.50 \\
7.11 & $10 \%$ OPC-2.8\% G & 6.20 \\
21.11 & $10 \%$ OPC-4.2\% G & 22.75 \\
\hline
\end{tabular}

Figure 4 shows the effect of Geosta ${ }^{\circledR}$ at OPC constant level. In the case of $5 \% \mathrm{OPC}$, it is observed that increasing the amount of Geosta ${ }^{\circledR}$, UCS also increases but never exceeds the values of only cement mixture. Concerning $7.5 \%$ OPC, the addition of $1.4 \% \mathrm{G}$ and $2.8 \%$ G keeps USC almost stable while with $4.2 \% \mathrm{G}$ a decrease has been observed. Las but not least, with much more OPC and more specifically with $10 \%$ OPC, there is a strong increase with $4.2 \% \mathrm{G}$.

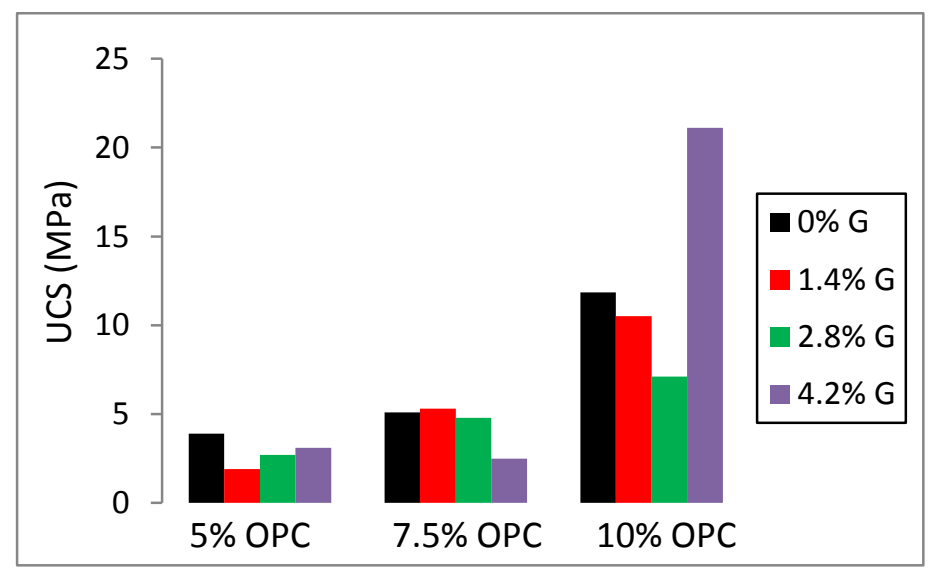

Figure 4. Effect of Geosta ${ }^{\circledR}$, for the 3 OPC levels considered, on UCS.

\section{Conclusion}

Based on the environmental and physical performance of the OPC/ Geosta $\AA$-treated $\mathrm{Ni}$ contaminated soil, the following conclusions can be drawn:

- All mix designs managed to retain $\mathrm{Ni}$ contamination below the trigger values proposed by ICRCL. Higher value is $58.4 \mathrm{mg} / \mathrm{kg}$ while lower value is $11.95 \mathrm{mg} / \mathrm{kg}$.
- The introduction of Geosta ${ }^{\circledR}$ into the $S / S$ treatment increased the ability of the binder system over $\mathrm{Ni}$ retention by more than two times, when compared to only cement mixtures (it is the case for all mixtures).

- This difference in retention ability between the plain cement mixtures and the ones containing Geosta ${ }^{\circledR}$ could be attributed to the cation exchange ability of chlorides (formation of heavy metal-Cl complexes) and zeolites (heavy metals are trapped inside the zeolitic structure) in Geosta ${ }^{\circledR}$ powder.

- The optimum mixture, in terms of chemical efficiency was $10 \%$ OPC wt $\%$ and 1.4 wt $\%$ of Geosta ${ }^{\circledR}$ with 5.57 $\mathrm{mg} / \mathrm{l}(11.95 \mathrm{mg} / \mathrm{kg})$ and $99.50 \%$ ratio of stabilization.

- In relation to the mechanical performance of $\mathrm{S} / \mathrm{S} \mathrm{Ni}$, higher UCS values were obtained when higher amount of cement $(10 \%$ OPC) was used for the solidification process

- The optimum mixture, in terms of mechanical efficiency, was $10 \%$ OPC wt $\%$ and 4.2 wt $\%$ Geosta ${ }^{\circledR}$ with 21.11 MPa.

- The optimum mixture in terms of reuse, leaching, UCS and cost is $5 \% \mathrm{OPC}-4.2 \% \mathrm{G}$ and has tremendous potential in construction material applications such as engineering fil, pavement blocks and bricks among others.

\section{References}

[1] S. K. Gupta and M. T. Surwade. "Immobilization of Heavy Metals from Steel Plating Industry Sludge Using Cement as Binder at Different pH," in Conf. on Moving Forward Wastewater Biosolids Sustainability: Technical, Managerial, and Public Synergy, New Brunswick, Jun. 2007, pp. 773 -777.

[2] R. B. Kogbara and A-T. Abir, "Mechanical and Leaching Behaviour of Slag-cement and Limeactivated Slag Stabilised/Solidified Contaminated Soil," Sci. of the Total Environment, vol. 409, no. 11, pp. 2325-2335, May 2011.

[3] Y. C. Yin, G. M. Shaaban and H. B. Mahmud, "Chemical Stabilization of Scrap Metal Yard Contaminated Soil Using Ordinary Portland Cement: Strength and Leachability Aspects," Building and Environment, vol. 42, no. 2, pp. 794802, Feb. 2007.

[4] S. Paria and P. K. Yuet, "Solidification/Stabilization of Organic and Inorganic Contaminants using Portland Cement: A literature review," Environmental Rev., vol. 14, no. 4, pp. 217-255, Oct. 2006. 
[5] K. E. Giller, E. Witter, and S. P. McGrath, "Toxicity of Heavy Metals to Microorganisms and Microbial Processes in Agricultural Soils: A Review," Soil Biology and Biochemistry, vol. 30, no. 10-11, pp. 1389-1414, Sep. 1998.

[6] P-C. Hsiau and S-L Lo, "Extractabilities of Heavy Metals in Chemically-Fixed Sewage Sludges," J. Hazardous Materials, vol. 58, no. 1-3, pp. 73-82, Feb. 1998.

[7] A. Kabata-Pendias and A. Mukherjee, Trace elements from soil to human, Pulawy, Poland: Springer-Verlag, 2007.

[8] K. Janicka and M. Cempel, "Effect of Nickel (II) Chloride Oral Exposure on Urinary Nickel Excretion and Some Other Element," Polish J. of Environmental Stud., vol. 12, no. 5, pp. 563-566, Feb. 2003.

[9] C. Aydinalp and S. Marinova, "Distribution and Forms of Heavy Metals in Some Agricultural Soils," Polish J. of Environmental Stud., vol. 12, no. 5, pp. 629-633, Mar. 2003.

[10] Y. C. Yin, A. Wan and Y. P. Lim, "Oil Palm Ash as Partial Replacement of Cement for Solidification/Stabilization of Nickel Hydroxide Sludge," J. Hazardous Materials, vol. 150, no. 2, pp. 413-418, Jan. 2008.

[11] G. E. Voglar and D. Lestan, "Efficiency Modeling of Solidification/Stabilization of Multi-metal Contaminated Industrial Soil Using Cement and Additives," J. Hazardous Materials, vol. 192, no. 2, pp. 753-762, Aug. 2011.

[12] E. E. Hekal, W. S. Hegazi, E. A. Kishar, and M. R. Mohamed, "Solidification/Stabilization of Ni(II) by Various Cement Pastes," Construction and Building Materials, vol. 25, no. 1, pp. 109-114, Jan. 2011.

[13] W. Shi, H. Shao, H. Li, M-A. Shaoa, and S. Du, "Progress in the Remediation of Hazardous Heavy Metal-Polluted Soils by Natural Zeolite," J. Hazardous Materials, vol. 170, no. 1, pp. 1-6, Oct. 2009.

[14] A. A. Mahabadi, M. A. Hajabbasi, H. Khademi, and H. Kazemian, "Soil Cadmium Stabilization Using an Iranian Natural Zeolite," Geoderma, vol. 137, no. 34, pp. 388-393, Jan. 2007.

[15] A. Shanableh and A. Kharabsheh, "Stabilization of $\mathrm{Cd}, \mathrm{Ni}$ and $\mathrm{Pb}$ in Soil Using Natural Zeolite," J. Hazardous Materials, vol. 45, no. 2-3, pp. 207-217, Feb. 1996.

[16] C. Belviso, F. Cavalcante, P. Ragone, and S. Fiore, "Immobilization of $\mathrm{Ni}$ by Synthesising Zeolite at
Low Temperatures in a Polluted Soil," Chemosphere, vol. 78, no. 9, pp. 1172-1176, Feb. 2010.

[17] NEN 7345 "Determination of the release of inorganic constituents from construction materials and stabilised waste products", in NNI (Formerly Draft NEN 5432), Delft, Netherlands, 1993.

[18] H. H. Rump, Laboratory Manual for the Examination of Water, Waste Water and Soil. Dunfermline, UK: Wiley-Vch, 2000.

[19] D. N. Little and S. Nair, (2009, August). Recommended Practice for Stabilization of Subgrade Soils and Base Materials, TRB Publication. Washington, D.C., USA. [Online]. Available:

http://onlinepubs.trb.org/onlinepubs/nchrp/nch rp_w144.pdf .

[20] M. F. Bertos, S. J. R. Simons, C. D. Hills, and P. J. Carey, "A Review of Accelerated Carbonation Technology in the Treatment of Cement-based Materials and Sequestration of C02," J. Hazardous Materials, vol. 112, no. 3, pp. 193-205, Aug. 2004.

[21] Z. Li, S. J. Roy, Y. Zou, and R. Bowman, "Long-Term Chemical and Biological stability of SurfactantModified Zeolite," Environmental Sci. \& Technol, vol. 32, no. 17, pp. 2628-2632, Jul. 1998.

[22] R. Terzavo, M. Spagnuolo, L. Medici, B. Vekemans, L. Vincze, K. Janssens, and P. Ruggiero, "Copper Stabilization by Zeolite Synthesis in Polluted Soils Treated with Coal Fly Ash," Environmental Sci. \& Technol., vol. 39, no. 16, pp. 6280-6287, Jul. 2005.

[23] E. Kontori, T. Perraki, S. Tsivilis, and G. Kakali, "Zeolite Blended Cements: Evaluation of their Hydration Rate by Means of Thermal Analysis," J. Thermal Anal. Calorimetry, vol. 96, no. 3, pp. 993998, Jun. 2009. 